\title{
Tipos, métodos e funções da avaliação no processo de ensino aprendizagem: uma
}

\section{análise bibliográfica}

\author{
Types, methods and functions in the teaching-learning process: a bibliographic analysis \\ Tipos, métodos y funciones de evaluación en el proceso de enseñanza-aprendizaje: un análisis \\ bibliográfico
}

Recebido: 04/07/2021 | Revisado: 09/07/2021 | Aceito: 12/07/2021 | Publicado: 13/07/2021

Lynda Poliana Moreira de Souza

ORCID: https://orcid.org/0000-0003-4777-1593

Prefeitura Municipal de Cariacica, Brasil

E-mail: lynda.souza@edu.cariacica.es.gov.br

\begin{abstract}
Resumo
A avaliação, que através de padrões pré estabelecidos qualifica e classifica determinado conceito ou sujeito, pode assumir incontáveis formatos, significados e propósitos no processo de ensino aprendizagem. Qual caminho escolher? O que fazer com os resultados? Como lidar com sentimentos e opiniões subjetivas? Como padronizar meios avaliativos em turmas heterogêneas? É possível medir o desempenho de um estudante através de uma escala numérica? São inúmeros questionamentos e, para estudar algo tão vasto, optamos por realizar uma pesquisa bibliográfica sistemática, procurando compilar estudos de especialistas no tema. Através dessa pesquisa foram ponderados os métodos de avaliação formal para conhecer a diversidade de instrumentos de avaliação, as impressões que professores e alunos têm sobre eles, sua eficácia e o lugar que ocupa no processo de ensino-aprendizagem. Agrupamos um repertório de pesquisas de diversos teóricos de imensa propriedade e credibilidade acadêmica para entender, analisar e contribuir com o enriquecimento da temática, auxiliando professores, gestores educacionais e pesquisadores na área da educação a lidar com o tema com maior fundamentação teórica.
\end{abstract}

Palavras-chave: Avaliação; Ensino; Critérios; Percepções; Finalidade.

\begin{abstract}
The evaluation that qualifies and classifies a particular concept or subject through pre-established standards can assume countless formats, meanings and purposes in the learning teaching process. Which path to choose? What to do with the results? How to deal with subjective feelings and opinions? How to standardize evaluative means in heterogeneous classes? Is it possible to measure a student's performance using a numerical scale? There are numerous questions and, to study something so vast, we chose to conduct a systematic bibliographic research, seeking to compile studies of specialists on the subject. Through this research, the formal evaluation methods were considered to know the diversity of assessment instruments, the impressions that teachers and students have about them, their effectiveness and the place they occupy in the teaching-learning process. We grouped a set of researches by several theorists of immense academic property and credibility to understand, analyze and contribute to the enrichment of the theme, helping teachers, educational managers and researchers in the area of education to deal with the theme with greater theoretical foundation.
\end{abstract}

Keywords: Evaluation; Teaching; Criteria; Perceptions; Purpose.

\begin{abstract}
Resumen
La evaluación que califica y clasifica un determinado concepto o asignatura a través de estándares preestablecidos puede asumir innumerables formatos, significados y propósitos en el proceso de enseñanza del aprendizaje. ¿Qué camino elegir? ¿Qué hacer con los resultados? ¿Cómo lidiar con sentimientos y opiniones subjetivas? ¿Cómo estandarizar las medias evaluativas en clases heterogéneas? ¿Es posible medir el rendimiento de un estudiante utilizando una escala numérica? Son numerosas las preguntas y, para estudiar algo tan vasto, optamos por realizar una investigación bibliográfica sistemática, buscando recopilar estudios de especialistas en la materia. A través de esta investigación, se consideró que los métodos formales de evaluación conocían la diversidad de instrumentos de evaluación, las impresiones que profesores y estudiantes tienen sobre ellos, su efectividad y el lugar que ocupan en el proceso de enseñanza-aprendizaje. Agrupamos un conjunto de investigaciones realizadas por varios teóricos de inmensa propiedad académica y credibilidad para comprender, analizar y contribuir al enriquecimiento del tema, ayudando a profesores, gestores educativos e investigadores del área de la educación a tratar el tema con mayor fundamento teórico.
\end{abstract}

Palabras clave: Evaluación; Enseñanza; Criterios; Percepciones; Propósito. 


\section{Introdução}

Considerando a amplitude de possibilidades de significados, definir "avaliação" torna-se algo difícil. Por ser essencialmente um julgamento de valor, está presente em nosso cotidiano de diversas maneiras e formas. Avaliar a hora certa de atravessar a rua, o custo benefício do investimento de um dinheiro na troca por um produto, a qualidade de uma comida ou serviço, são exemplos disso. (Swanwick, 2003). Mesmo quando estreitamos essas possibilidades, ou seja, quando consideramos somente a maneira formal de avaliar, a que acontece dentro de uma instituição de ensino, nos deparamos com outro número de significados. Pode ser a avaliação da aprendizagem, avaliação do rendimento escolar, avaliação do aluno, do método, do professor, do processo e ensino-aprendizagem. Aumentamos ainda mais essa teia se consideramos que existem inúmeros instrumentos (provas, exercícios, seminários) e inúmeros critérios (comportamento, participação, estética, organização). Portanto, diante disso, focaremos nossas análises na avaliação como sendo um procedimento de responsabilidade da instituição escolar, que visa obter um diagnóstico do processo de ensino e aprendizagem dos alunos, em relação à programação curricular prevista e desenvolvida em cada nível e etapa de escolaridade.

Não analisaremos o processo de ensino aprendizagem. Não diretamente, porque esse é um vetor essencial para obtenção dos resultados que buscamos. Afinal, o processo avaliativo enquanto processo formativo é parte integrante do processo [de ensino aprendizagem]. (Abem n5 set 2000, p. 24). Nosso foco será na forma com que a avaliação foi realizada, seus instrumentos, métodos, critérios, como foi recebida, e principalmente sua validade, como seus resultados foram encarados. Sabemos que o senso comum traz em si uma certeza inerente, nem sempre verdadeira e verificável quando passada pelas lentes críticas do método científico. (Becker, 1997). A fim de alcançar esses objetivos e sanar incertezas e inquietações que nos guiaram a esse estudo, recorremos à literatura para uma fundamentação teórica.

\section{Metodologia}

A importância da avaliação não pode ser negligenciada já que é parte do processo de ensino e aprendizagem. A maneira que a avaliação é vista, ministrada, tratada e concebida pode mudar os rumos de cada estudante, sua interação com os outros alunos, sua aprendizagem, sua relação com a matéria e o professor, seu futuro estudantil. Esperamos com essa pesquisa conhecer alguns métodos de avaliação, seus papeis no cotidiano do processo de educação. Para alcançar esses objetivos, o método escolhido é a pesquisa bibliográfica de cunho exploratório, e para tanto, selecionamos fontes relevantes e confiáveis de grande renome na área da pesquisa e da educação para servir de base fundamental para analisar e levantar dados, informações, conceitos e convicções baseados no senso critico e no critério científico. Assim, entre o final de 2020 e meados de 2021, houve uma revisão bibliográfica de materiais já elaborados (em língua portuguesas encontrados em plataformas científicas ou na biblioteca da Universidade Federal do Espírito Santo) criando assim uma compilação de estudos que dão enriquecimento à discussão, trazendo inúmeros pontos de vista e abordagem multidimensionais a um fenômeno também múltiplo. Procuramos não hierarquizar as idéias ou confrontar autores com escolas diferentes, mas criar um quadro teórico de apoio analítico e fornecer uma estrutura básica para pesquisas futuras sobre o tema.

\section{Resultados e Discussão}

\subsection{Avaliação: inúmeros conceitos, múltiplos objetivos, muitas possibilidades}

Tenho o direito de ter raiva, de manifestá-la, de tê-la como motivação para minha briga tal qual tenho o direito de amar, de expressar meu amor ao mundo, de tê-lo como motivação de minha briga porque, histórico, vivo a História como tempo de possibilidade e não de determinação. (Freire, 2009, p. 75) 
A Base Nacional Comum Curricular é um documento que visa garantir o direito de aprendizagem de habilidades conteúdos essenciais a todos estudantes do território nacional. A BNCC está prevista da LDB - Lei de Diretrizes e Bases da Educação Nacional e deve ser referência a todos currículos das redes públicas e particulares. Para que o currículo seja real, entre em ação, deve haver um conjunto de decisões que adéquam as propostas à realidade local, considerando as particularidades e peculiaridades das regiões e das instituições e sistemas de ensino, alem, é claro, das características dos alunos. Essas ações, citadas na introdução da BNCC, são, entre outras: contextualizar os conteúdos e criar estratégias para apresentá-los, organizar os componentes curriculares de forma interdisciplinar, usar estratégias didático-pedagógicas diversificadas, e "construir e aplicar procedimentos de avaliação formativa de processo ou de resultado que levem em conta os contextos e as condições de aprendizagem, tomando tais registros como referência para melhorar o desempenho da escola, dos professores e dos alunos".

A avaliação formal pode adotar diferentes significados, instrumentos, critérios, objetivos e importância. Pode ser dada através de provas ou trabalhos, escritos ou orais; exercícios práticos ou teóricos; em sala ou não; em grupo ou individualmente. O que se avalia desses instrumentos, como conteúdo, estética, organização, pode ainda nos dar um número incontável de combinações. (Gentile \& Andrade, 2001). No livro “Metodologia da Avaliação em Políticas Públicas” Izaura Belloni et al, (p. 16, 2001). faz algumas considerações sobre o termo avaliação e diz que

Avaliação educacional refere-se à avaliação de aprendizagem de desempenho escolar ou profissional onde indivíduos ou grupos submetidos a processo ou situações com vistas à aquisição de novo conhecimento, habilidade ou atitude.

A distância entre teorias e realidade cotidiana das escolas condicionadas estruturalmente pelo sistema de promoção e seriação, na visão de José Eustáquio Romão (1998) é o motivo de tantas concepções sobre avaliação. Se tentarmos levantar os diversos conceitos de avaliação da aprendizagem, certamente encontraremos tantos quantos são seus formuladores.

Segundo Romão (1998, p. 34), Graduado em História, Doutor em Educação e coordenador do Grupo de Pesquisa "Culturas e Educação" Talvez, por isso mesmo, surjam tantas concepções de avaliação, sempre vagamente implicadas nas formulações verbais de professores, alunos e pais,que a identificam com tudo que ocorre nas práticas correntes: prova, nota,conceito, boletim, aprovação, reprovação, recuperação etc.

Muitos professores nem mesmo são conscientes da reprodução de um modelo, agindo sem questionamento, sem reflexão, a respeito do significado da avaliação na escola (Hoffman, 2011). Na formação permanente dos professores o momento fundamental é o da reflexão crítica sobre a prática. Avaliação exige compromisso de ensinar. E ensinar exige "decência e boniteza de mãos dadas"; de escolher, de decidir, de fugir dos desvios da verdade dos caminhos fáceis. Para Freire (2009), ensinar exige um "movimento dinâmico, dialético entre o fazer e o pensar sobre o saber". (p. 33, 38) Contudo, a avaliação não tem um fim em si mesmo. Para Libâneo (1994, p. 195) que tem uma vasta formação acadêmica e experiências profissionais na área da educação, a avaliação deve ser encarada como um referencial que sirva de base para análises e autoanálises e assim, direcione ou mude o rumo das propostas, se necessário, nos comprometemos em averiguar e problematizar o trato dado aos resultados dessas avaliações.

Na visão de Clarilza Prado de Souza (1994) graduada em psicologia e doutora em educação, avaliação é "uma prática valiosa quando tem o propósito de compreender o processo de aprendizagem que o aluno está percorrendo em um dado curso, e quanto se tem intenção de modificar, recursos e práticas educativas tomando um novo compromisso com os objetivos."

A avaliação serve para verificar as mudanças, bem como a quantidade ou grau de mudança ocorrido em cada aluno. Mas deve-se levar em conta não só o produto, o resultado, mas o caminho. O tratamento é dado aos resultados obtidos pelos alunos é tão importante quanto o método utilizado. Acreditamos que a avaliação deva subsidiar o sistema educacional como um todo - professor, a equipe escolar e o aluno - no aperfeiçoamento do ensino, e não apenas servir de indicador numérico da 
capacidade individual de cada aluno, como se esse pudesse ser visto de forma isolada, nesse emaranhado de relações e acontecimentos que o cercam em todos os âmbitos de sua vida, inclusive o escolar. (Libâneo, 1994, p. 197).

Afinal, como disse Swanwick (2003, p. 81), “a função da avaliação é guiar todas nossas ações”. Jussara Hoffmann que desenvolveu estudos e pesquisas em avaliação e educação infantil na Faculdade de Educação da UFRGS e atua como conferencista e consultora educacional, tendo atuado em mais de 500 congressos e eventos no país e no exterior, também levanta a idéia da finalidade da avaliação distinguindo entre avaliação como controle que cerceia e avaliação como controle que acompanha. A última está a favor do aluno, trata de um rigor "terno e amoroso" que acompanha o aluno em seu percurso. Dialógica, estimula a superação de desafios. A outra intimida e cerceia (Hoffmann, 2001).

Segundo Hiran Pinel et al (2011), doutor em Psicologia escolar e do desenvolvimento humano pelo Instituto de Psicologia da Universidade de São Paulo - IP/USP e mestre em Educação (desenvolvimento humanos e processos educacionais) pelo Programa de Pós-Graduação em Educação da Universidade Federal do Espírito Santo - PPGE/ UFES a avaliação do processo ensino/aprendizagem tem sido pautada pela lógica da mensuração, isto é, associa-se o ato de avaliar ao de "medir" os conhecimentos adquiridos pelos alunos. O professor assume um papel técnico de mensurar, e os exames, de classificar.

Luckesi que já publicou diversos trabalhos científicos na érea de filosofia, metodologia e educação, trata da "pedagogia do exame", que substitui a pedagogia do ensino aprendizagem, da produção do conhecimento, passando a ser o centro controlador, transformando-se em instrumento de poder do professor. Ou seja, ele critica a avaliação quando essa se torna mais importante do que o processo de ensino-aprendizagem, sugerindo que a avaliação tomou uma roupagem ameaçadora e que legitima toda uma ideologia conservadora. Sendo assim, o aluno buscar superar o obstáculo "prova", e não superar a si mesmo numa comparação com níveis anteriores na busca pela acumulação do aprendizado e pelo crescimento pessoal (Luckesi, 2005).

Freire, educador e filósofo brasileiro que influenciou o movimento chamado "pedagogia crítica" fala em "pedagogia dos dominantes" x "pedagogia dos oprimidos". A primeira se baseia numa concepção "bancária", onde o professor "deposita" o saber e o "saca" na hora da prova. Só o professor sabe, é uma relação vertical, ocorre de cima para baixo. Na segunda, o ato de conhecer não é uma "doação" do educador, mais um processo que se estabelece no contato do educando com o mundo vivido, que se encontra em transformação. (Freire, 2008, p. 38).

A avaliação não deve limitar-se à aplicação de um instrumento de coleta de informações. (SOUZA, 1994) Na sala de aula deveria predominar o diagnóstico como recurso de acompanhamento e reorientação da aprendizagem, em vez de predominarem os exames como recursos classificatórios. "Seja pontual ou contínua, a avaliação só faz sentido quando provoca o desenvolvimento do educando" (Luckesi, 2003).

\subsection{Aspectos emocionais no processo de avaliação}

A avaliação é um fenômeno humano, interpessoal, e por isso, não está isenta de opiniões, sentimentos, histórias de vida, personalidades, emoções. Num jogo interessante de metáforas, Clarilza Prado de Souza (1994) diz que a avaliação, assim como os remédios, tem propriedade: pode produzir reações adversas e efeitos colaterais. Diz ainda que além de haver uma maneira certa de empregá-la (posologia), devem ser tomadas precauções ao utilizá-la, porque que existem indicações e contraindicações.

Seguindo o tom dessa discussão, precisamos dar mais relevância às emoções relacionadas ao processo de avaliação da aprendizagem, tais como o medo, a tensão, a alegria, a tristeza, a felicidade, que nos permitiram propor indagações, a serem levantadas quando se avalia. Além de ter que elaborar a pergunta ideal, no método perfeito, de perceber individualidades, de 
corrigir opiniões e maneiras de escrever e olhar o mundo, o certo e o errado, de classificar, mensurar de forma justa, e talvéz por isso mesmo, os professores também estão sujeios às emoções que a avaliação faz emanar.

\subsection{Avaliar é medir? Criticas ao processo e aos objetivos}

E tudo isso nos traz de novo à radicalidade da esperança. Sei que as coisas podem até piorar, mas sei também que é possível intervir para melhorá-las. (Freire, 2009, p.52)

Jussara Hoffman diz que avolumam-se as inquietudes em volta da avaliação educacional porque novos rumos para a educação se fazem necessários (Hoffmann, 2001). Na formação permanente dos professores o momento fundamental é o da reflexão crítica e permanente sobre a prática. Muitos professores nem mesmo são conscientes da reprodução de um modelo, agindo sem questionamento, sem reflexão, a respeito do significado da avaliação na escola (Hoffman, 2011). Avaliação exige compromisso de ensinar. E ensinar exige "decência e boniteza de mãos dadas"; de escolher, de decidir, de fugir dos desvios da verdade dos caminhos fáceis. Para Freire (2009), ensinar exige um "movimento dinâmico, dialético entre o fazer e o pensar sobre o saber". (p. 33, 38)

Medir significa atribuir um número a um acontecimento ou a um objeto, de acordo com uma regra logicamente aceitável (p.27). Dessa forma não se deve denominar por avaliação testes, provas ou exercícios (instrumentos de avaliação). Muito menos se deve nomear por avaliação boletins, fichas e relatórios. Isso é medir. O conhecimento e a mensuração de sua aquisição por parte do aluno são extremamente complexos. Contudo, a utilização do parâmetro "objetivos" e a confiabilidade nessas medidas (mais da parte dos professores que dos alunos) mostra que a avaliação é sinônimo de medida do desempenho. Maria da Graça Nicoetti Mizukami (1986) no livro "Ensino: as abordagens do processo" se dedica a explicar algumas categorias no contexto das práticas educativas como homem, mundo, sociedade, cultura, conhecimento, educação, escola, ensino aprendizagem, professor, aluno, metodologia e avaliação. (p. 17 e 82) e diz que "A avaliação é realizada predominantemente visando a exatidão da reprodução do conteúdo comunicado em sala de aula. Mede-se, portanto, a quantidade e exatidão de informações que se consegue reproduzir".

O exame passa a ter um fim em si mesmo e o ritual é mantido. As notas obtidas funcionam, na sociedade, como níveis de aquisição do patrimônio cultural. A instituição e conseqüentemente os professores adotam o sistema de notas. Esse não só porque são obrigados pelo sistema, mas porque planejam e executam seus planos de aula com essa filosofia metodológica. Segundo Hiram Pinel et al (2011) a medida é um passo inicial, às vezes bastante importante, mas não é condição necessária, e nem suficiente, para que a avaliação se efetue.

$\mathrm{Na}$ avaliação exata, classificatória e numérica, desconsidera-se em grande medida a subjetividade que envolve os sujeitos desse processo; que a bagagem emocional, visão de mundo, interesses e capacidade de expressá-los, de cada indivíduo, interfere nos resultados da avaliação. Para não dizer dos motivos fisiológicos, como deficiências visuais e auditivas, traumas, comportamentos psicossomáticos, que não contemplaremos nesse estudo.

Constatamos que os alunos estudam na véspera, somente o suficiente, o que pode ser um sintoma de falta de interesse, de irresponsabilidade, desorganização do tempo ou desmotivação. Além do mais, não há uma busca pela excelência, já que a média é suficiente para permitir que o aluno avance para outro estágio. Com essa dinâmica, o que observamos, são alunos em busca das notas, mesmo que seja na recuperação, na prova final. Sobre esse sistema de notas, Mariano Enguita (1995) diz que "a escola prega a avaliação diagnóstica, que serve como indicador de uma possível reformulação no processo de ensinoaprendizagem, mas emprega a avaliação classificatória".

Vimos que apesar dos critérios de correção serem compartilhados, é pequena a freqüência da retomada dos conteúdos para aperfeiçoamento do tema tanto por parte do professor quanto por parte do aluno. Os professores e alunos não se 
mobilizam para reforço do tema e a recuperação, quando ocorre, é de notas, e não dos conteúdos. Para José Carlos Libâneo (1994), a avaliação é vista como atribuição de notas, via provas, e ganha uma dimensão de medida. E Luckesi (2005) completa dizendo:

Em síntese, as observações até aqui desenvolvidas demonstram que a aferição da aprendizagem escolar é utilizada, na quase totalidade das vezes, para classificar os alunos em aprovados ou reprovados. E nas ocasiões onde se possibilita uma revisão dos conteúdos, em si, não é para proceder a uma aprendizagem ainda não realizada ou ao aprofundamento de determinada aprendizagem, mas sim para "melhorar" a nota do educando e, por isso, aprová-lo.

Em nenhum momento há a preocupação efetiva com o aprofundamento no assunto, com a aquisição do conhecimento. Um investimento no sistema numérico, quantitativo e não qualitativo. Assim, alunos que não se adaptaram aos métodos de aula, ou aos próprios instrumentos de avaliação, acabam excluídos; nesse caso, reprovados, assumindo toda a culpa que deveria ser dividida com o sistema. Swanwik (2003) também segue essa tendência e diz que é necessário que se estabeleçam critérios confiáveis e uma linguagem compartilhada para se justificar todos os passos do processo avaliativo. O modelo válido deve ser verdadeiro e confiável; permitir compreender o que acontece na sala de aula, em todo o processo de ensino aprendizagem. De fato, restringir-se a exames pontuais com atribuição de notas e calcular a média dos resultados não mede a quantidade nem a qualidade do aprendizado. É um jeito velho (e ultrapassado) de enxergar o ensino. (Gentile \& Andrade 2001). "A nota é apenas uma representação simplificada de um momento do processo de aprendizagem. O que vale é o crescimento do aluno em relação a sim próprio e aos objetivos propostos" (Sandra Záckia de Souza citada por Gentile e Andrade, 2001).

O que observamos também, é que algumas estratégias de avaliação tomaram rumos ineficazes, do ponto de vista da aprendizagem efetiva. O que se cobra é uma devolução da informação; uma avaliação que pretende averiguar o quanto o aluno ainda lembra-se do que foi dito e feito em sala de aula. É uma constatação da capacidade de guardar informações na memória (Libaneo, 1994, p. 198) Em "Nossa escola é uma calamidade”, Darcy Ribeiro (1984), antropólogo, escritor e político, o exame, a prova, são sistemas perversos que se baseiam no que ele chama de "competentômetro", que ingenuamente mede até o centésimo a competência de seus alunos (p. 62). Ele diz

Decoreba, que leva o professor a exigir do aluno a memorização de quantidades espantosas de informações inúteis que ele esquecerá cuidadosamente logo depois da prova. O próprio professor só se lembra dela porque tem em mãos o seu livro-cola. (p. 61)

A maioria dos alunos acha a avaliação necessária no processo de ensino apesar de não achá-la um diagnóstico fiel daquilo que aprendeu. Declararam ainda, que não se lembra do conteúdo por muito tempo depois da avaliação demonstrando que não serve como condensador do aprendizado. Isso reforça que a avaliação deve ser encarada como diagnóstico individual e coletivo do processo para tomada de decisões que otimizem a busca pelos objetivos. Contudo, os próprios alunos ofereceram a solução: o envolvimento prático com o conteúdo, a experiência com o assunto, faz com que esse seja internalizado, que receba atributos de função, propriedades de utilidade. Freire enxerga o professor como alguém que deve incitar o aluno produzir a compreensão do objeto. Para ele, ensinar não é transmitir conhecimento (Freire, 2009, p. 119), e assegura:

É por isso, repito, que ensinar não é transferir conteúdo a ninguém, assim como aprender não é memorizar o perfil do conteúdo transferido no discurso vertical do professor. Ensinar e aprender tem que ver com o esforço metodicamente crítico do professor de desvelar a compreensão de algo e com o empenho igualmente crítico do aluno de ir entrando como sujeito em aprendizagem, no processo de desvelamento que o professor ou professora deve deflagrar. 
A avaliação, mesmo que com prova individual, não avalia somente o aluno, mas o sistema; não demonstra somente a capacidade individual do estudante, mas serve para compreender o processo de aprendizagem que ela está percorrendo. Os alunos não consideram a avaliação como instrumento adequado para medir graus de aprendizagem; que é distante, inadequado para mensura algo subjetivo. A falta de tempo, de motivação, psicoemocionais, a falta de dedicação, avaliações sem prestígio e conteúdos sem importância apareceram como motivos que dificultam o desempenho durante as atividades. Sendo que um bom percurso didático e métodos como revisões, debates e aulas práticas declaram abertamente que o processo de avaliação é uma parte do todo. Sobre isso, Hoffmann (2001) declara:

O aluno no processo de aprendizagem tem que ter a consciência de se perceber aprendendo e de querer aprender mais. Portanto, ele não pode aprender para alguém ou para alguma coisa, mas aprender pelo prazer da curiosidade, da superação intelectual, aprender para si próprio e para a vida.

Segundo Jussara Hoffman a ação avaliativa deve partir do fazer do aluno, provocação necessária ao processo de compreender. (Hoffman citada por Pinel et al, 2011). No capítulo "Processos metodológicos" Paulo Freire fala do método de alfabetização que pensou e desenvolveu para ser um ato de criação, capaz de gerar outros atos de criação (2009, p. 41). Esse novo método the rendeu bons resultados e boas críticas porque o aluno não era passivo. Como ele mesmo explica (p. 41) " Procurávamos uma metodologia que fosse um instrumento do educando, e não somente do educador, e que identificasse o conteúdo da aprendizagem com o processo mesmo de aprender". A alusão aqui cabível a essa experiência se dá para pensarmos num processo de ensino inclusivo e numa avaliação abrangente, que contemple os saberes, que seja participativa, que faça sentido na realidade acadêmica, profissional e pessoal; que possa ser vivida e vivenciada. A avaliação da aprendizagem envolve e diz respeito diretamente a dois elementos do processo: educador/ avaliador e educando/avaliando. $\mathrm{O}$ pensar certo não é presente dos deuses ou dos professores, mas, a superação do ingênuo tem que ser produzido pelo próprio aprendiz em comunhão com o professor (Freire, 2009, p. 39). Jussara Hoffmann (2001) diz que é a "prática dialética que favorece o crescimento do aluno e do professor, que indiretamente se analisa, e revendo seus conceitos, pode aperfeiçoá-los e adequá-los”.

A avaliação deve ter uma intenção, ser pressuposto para a continuidade do processo de aprendizagem e causar reformulações constantes das propostas pedagógicas. Portanto, precisa ser contínua e não por etapas pré-delimitadas, como se o aprendizado do aluno fosse aparelhado e organizado em bimestres, semestres e anos letivos. Deve haver do professor uma consciência e compromisso com os alunos e seu progresso em termos de aprendizagens.

Observamos também a desvalorização das auto-avaliações. Nela, o aluno mesmo traça seus objetivos e assume a responsabilidade de "controle de sua aprendizagem". (Mizukami, 1986, p. 56). Define critérios e avalia se seus objetivos estão sendo atingidos. Mizukami considera que só o indivíduo pode conhecer realmente sua experiência, esta só pode ser julgada a partir de critérios internos do organismo; critérios externos podem propiciar um desajustamento (p. 55). E Roger (1972, p. 5 citado por Mizukami , 1986, p.55) diz:

Quando reunimos em um esquema elementos tais como currículo preestabelecido, "deveres idênticos", para todos os alunos, preleções como quase único modo de instrução, testes padronizados pelos quais são avaliados todos os estudantes, então, quase podemos garantir que a aprendizagem, dotada de significação, será reduzida à sua expressão mais simples.

Cabe ao professor, além de compreender a forma como se dá a aprendizagem o que o aluno precisa fazer para ser o sujeito protagonista de seu processo de aprender é mover-se. É claro que para tal movimento do aluno há a necessidade da criação, por parte dos professores, das condições que lhe desperte e encante. Jussara Hoffman (2011) denomina "avaliação 
mediadora" como oposição total a avaliação sentenciosa, classificatória. Sob essa nova perspectiva repousa a mutualidade. A conjugação de idéias, esforços, saberes, maneiras. A autora defende:

O que pretendo introduzir neste texto é a perspectiva da ação avaliativa como uma das mediações pela qual se encorajaria a reorganização do saber. Ação, movimento, provocação, na tentativa de reciprocidade intelectual entre os elementos da ação educativa. Professor e aluno buscando coordenar seus pontos de vista, trocando idéias, reorganizando-as.

Nessa perspectiva o erro é construtivo. Sejam respostas certas ou erradas, representam manifestações dos alunos e demandam considerações mais aprofundadas por parte do professor, que não apenas atribuição de notas (HOFFMAN, 2011). Concordando com essa perspectiva, Romão (1998, p.59) declara;

Na educação libertadora, a avaliação deixa de ser um processo de cobrança para se transformar em mais um momento de aprendizagem, tanto para o aluno quanto para o professor - mormente para este, se estiver atento aos processos e mecanismos de conhecimento ativados pelo aluno, mesmo no caso de "erros", no sentido de rever e refazer seus procedimentos de educador.

A avaliação mediadora acontece em três tempos. O primeiro trata de fazer um diagnóstico da turma; de cada aluno. O que ela chama de "tempo de admiração". Alunos diferentes, necessidades e potencialidades diferentes.No segundo momento, há o "tempo de reflexão", onde o professor se posiciona como intérprete dessas manifestações, e de si mesmo, de suas propostas, a fim de oferecer um ambiente propício e provocar o interesse do aluno. A seguir, há o "tempo de reconstrução", a abertura para a inovação, para a adequação. Um planejamento que é rigoroso mais acolhedor; que contempla o diverso, que respeite o discurso contrário. Observar o aprendiz, analisar e compreender suas estratégias, de aprendizagem, tempo e interesses, tomar decisões pedagógicas favoráveis à continuidade do processo.

Como afirma Clarilza Prado de Souza (1994), o aperfeiçoamento do ensino é uma das funções essenciais da avaliação, contudo, adotar uma filosofia de classificação é mais cômodo, no sentido de descomprometer toda equipe pedagógica com esse objetivo.Apesar disso, a apreciação das notas e discussões dos resultados para tomada de decisões não devem girar somente sobre os instrumentos e meios de diversificá-los ou dificultá-los, por exemplo. O que se deve ter em mente, é que, para cumprir sua real proposição, e ser útil na evolução de práticas de ensino, a avaliação deve transcender a mera contabilidade das notas. Luckesi (2005) completa essa idéia quando afirma:

De fato, o ideal seria a inexistência do sistema de notas. A aprovação ou reprovação do educando deveria dar-se pela efetiva aprendizagem dos conhecimentos mínimos necessários, com o conseqüente desenvolvimento de habilidades, hábitos e convicções. Entretanto, diante da intensa utilização de notas e conceitos na prática escolar e da própria legislação educacional que determina o uso de uma forma de registro dos resultados da aprendizagem, não há como, de imediato, eliminar as notas e conceitos da vida escolar.

Mere Abramowicz (1994) mestre em Supervisão Currículo pela Pontifícia Universidade Católica de São Paulo e doutora em Educação (Psicologia da Educação) pela mesma universidade, considera que o conceito de avaliação da aprendizagem, deva evoluir de uma faceta tecnicista em que avaliar significava medir, atribuir nota, classificar, para uma concepção de avaliação crítica vista em um contexto sociopolítico-cultural mais amplo, historicamente situada, autoconstruída, transformadora e emancipadora. Ou seja, o aluno não precisa necessariamente reproduzir o que observa, o que aprende, o que pratica."Nada do que experimentei em minha atividade docente deve necessariamente repetir-se", declara. (FREIRE, 2009, p. 50). Apreender a realidade não para adaptar, mas para transformar, para intervir, recriar. A avaliação, mesmo que com 
prova individual, não avalia somente o aluno, mas o sistema; não demonstra somente a capacidade individual do estudante, mas serve para compreender o processo de aprendizagem que ela está percorrendo.

Além disso, o que se pretende com análise do processo avaliativo é mensurar a eficiência/ eficácia das propostas, não somente no que diz respeito aos resultados alcançados pelos alunos mas ao trato dado a esses resultados. Inquirir qual tratamento é dado aos resultados obtidos pelos alunos é importante porque a avaliação deve subsidiar o sistema educacional como um todo - professor, a equipe escolar e o aluno - no aperfeiçoamento do ensino, e não apenas servir de indicador numérico da capacidade individual de cada aluno, como se esse pudesse ser visto de forma isolada, nesse emaranhado de relações e acontecimentos que o cercam em todos os âmbitos de sua vida, inclusive o escolar. Segundo Swanwick a função da avaliação é guiar todas nossas ações. (Swanwick, 2003). Libâneio corrobora com essa ideia dizendo que "através dela [avaliação], os resultados que vão sendo obtidos no decorrer do trabalho conjunto do professor e dos alunos são comparados com os objetivos propostos, a fim de constatar progressos, dificuldades, e reorientar o trabalho para as correções necessárias" (1994, p.195).

\section{Considerações Finais}

A educação é um processo com muitos autores e muitas etapas. Uma delas é a avaliação. Ela serve, falando de forma simples, como forma de mensurar o que se apreendeu do que foi ensinado e trazer informações sobre como prosseguir. Não há um modelo certo e outro reprovável e evitável, e cabe a todos os autores envolvidos entenderem bem seus objetivos para que isso funcione como parte essencial do processo, e não como métodos de repreensão, hierarquização ou punição que não contribuem para que processo de ensino aprendizagem ocorra de forma adequada.

O objetivo desse trabalho foi conhecer e compilar uma diversidade de instrumentos de avaliação, as impressões que professores e alunos têm sobre eles, sua eficácia e o lugar que ocupa no processo de ensino-aprendizagem sobre a luz de pesquisas científicas já consolidadas. Mais especificamente pretendemos, apoiados em teóricos que tratam do assunto, fornecer base teórica para futuros empreendimentos de pesquisa sobre o tema, que busquem problematizar e analisar vieses dessa temática, como: conhecer a diversificação dos instrumentos de avaliação; os processos e critério de apuração; quais objetivos o professor possui com aquele tipo de avaliação; quais esforços demonstrados pelo aluno para realização da avaliação; o que acontece com os resultados das avaliações para ambos, professores e alunos; se há uma auto-avaliação, tanto do professor quanto do aluno; o que acontece se for verificado dificuldades na realização do exame, ou em se alcançar determinados objetivos; se seus níveis de aprendizado anteriores são considerados e comparado sua evolução; o que a avaliação gera como sentimento, no aluno; como a afetividade e as emoções, em geral, se expressam no processo avaliativo; o que fica, no aluno, do processo de avaliação.

Para Freire, é possível reconstruir um mau aprendizado, o em que o aprendiz foi puro paciente da transferência do conhecimento feita pelo educador (Freire, 2009 p.69). Não deve haver a preocupação com critérios exatos e predefinidos. Por outro lado, a observação do professor não deve ser seu único apoio na hora da avaliação (Hoffman, 2011). Caso o resultado da avaliação não tenha validade (não seja analisado, discutido), caso não sirva de base para tomada de atitudes, mas somente para delimitar e classificar os alunos, isso comprovará que tomou um lugar de destaque no processo educacional, que deveria ser da aprendizagem efetiva dos conteúdos. (Libaneo, 1994) Sendo assim, a avaliação tornar-se ia mais importante do que o processo de ensino-aprendizagem, e ainda, que tomaria uma roupagem ameaçadora que legitima toda uma ideologia conservadora.

Observamos que, apesar de numerosos pontos de vista dos autores recorridos, há uma consonância de pensamentos que converge em tratar a avaliação não como uns instrumento com fim em si mesmo, mas como um mecanismo analítico que ajuda no planejamento visando transformar efetivamente conteúdos em habilidades e competências. Ou seja, é um exame de 
todo processo de ensino-aprendizagem e de todos seus autores, considerando se houve êxitos no alcance dos objetivos propostos pelo professor e/ou pela instituição, e não somente pelo aluno.

Concordamos que o processo avaliativo deva ser dinâmico, contínuo, consciente, e que deva transcender a mera contabilidade das notas e provas. Ou seja, servir apenas como aplicação de instrumentos de coleta de dados. A avaliação deve fazer com que a equipe escolar, e o próprio aluno, se comprometam com a tomada de decisões que visem o aperfeiçoamento do ensino e seu melhor aproveitamento. Deve ser encarada como um referencial que sirva de base para análises e auto-análises e assim, direcione ou mude o rumo das propostas, se necessário.

Para Freire, a educação deve estimular a opção e afirmar o homem como homem. "Adaptar é acomodar, não transformar" (Freire, 2008, p. 32). Não somos contra a avaliação, já que é um meio de evidenciar o nível do aprendizado, e dar dados necessários para tomada de decisões, mas não são somente os instrumentos que devem melhorar. O aluno deve aprender a aprender, além de aprender a se auto-avaliar (Souza, 1994). Porque, se utilizada de forma transparente e participativa, permite também ao aluno reconhecer suas próprias necessidades, desenvolver a consciência de sua situação escolar e orientar seus esforços na direção dos critérios de exigência da Escola.

\section{Referências}

Abramowicz, M. (1994). Participação e avaliação em uma sociedade democrática multicultural. Centro de Referência em Educação Mário Covas.

Becker, H. S. (1999). Métodos de pesquisa em ciências sociais. (4a ed.), Hucitec.

Belloni, I., Magalhães, H. \& Sousa, L. C. (2001). Metodologia de avaliação em políticas públicas: uma experiência em educação profissional. (2a ed.), Cortez.

Enguita, M. (1995). Avaliação e aprendizagem. Centro de Referência em Educação Mário Covas.

Freire, P. (2008). Educação e Mudança. (31a ed.), Paz e Terra.

Freire, P. (2009). Pedagogia da autonomia: saberes necessários à prática educativa. Paz e Terra.

Hall, S. (2005). A identidade cultural na pós-modernidade. (10a ed.), DP\&A.

Hoffmann, J (1997). Avaliação mediadora: uma pratica em construção da pré-escola a universidade. (11a ed.), Mediação.

Hoffmann, J. (2001). Avaliar Para Promover: as setas do caminho. Mediação.

Libâneo, J. C. (1994). Didática. Cortês.

Luckesi, C. C. (2005). Avaliação da aprendizagem... mais uma vez. Artigo publicado na Revista ABC EDUCATIO nº 46.

Mizukami, M. G. N. (1986). Ensino: as abordagens do processo. E. P. U.

Pinel, H., et al. Avaliação da aprendizagem na educação de jovens e adultos: buscando sentidos. https://www.anpae.org.br/simposio2009/63b.pdf.

Ribeiro, D. (1984). Nossa escola é uma calamidade. Salamandra.

Romão, J. E. (1998). Avaliação dialógica: desafios e perspectivas. Cortez: Instituto Paulo Freire.

Santos, C. G. A., Hentschke, L. \& Fialkow, N. (2000). Avaliação da execução musical: relação entre as concepções e práticas adotadas por professores de piano. Abem, n. 5.

Saul, A. M. A. (1994). Avaliação educacional. Centro de Referência em educação Mario Covas. Publicação: Série Idéias n. 22. FDE. http://www.crmariocovas.sp.gov.br/pdf/ideias_22_p061-068_c.pdf.

Saul, A. M. (1988). Avaliação emancipatória: desafio à teoria e à prática de avaliação e reformulação de currículo. São Paulo: Cortês: Autores Associados. Souza, C. P. (2001). Avaliação escolar: limites e possibilidades. Centro de Referência em Educação Mário Covas. http://www.crmariocovas.sp.gov.br/pdf/ideias_22_p089-090_c.pdf.

Souza, C. P. (1991). Avaliação do rendimento escolar. Papirus.

Swanwick, K. (2003). Ensinando música musicalmente. Moderna.

Libâneo, J. C. (1994). Didática. Cortez. 